\title{
ABOUT SUBJECTIVITY IN QUALITATIVE DATA INTERPRETATION
}

\author{
Ştefania BUMBUC \\ “Nicolae Bălcescu” Land Forces Academy, Sibiu, Romania \\ stefanabumbuc@gmail.com
}

\begin{abstract}
Some of the most commonly used methods of gathering data during the qualitative research of the social field are observation, documents analysis, interview, focus group, and case study. In this paper we analyze some relevant aspects of these research methods, in order to highlight their advantages and disadvantages in respect of the depth and extension of collected data, and also in respect of the reliability of the data processing. The subjectivity is always present in the qualitative research, but this is not necessary bad things, as long as the researchers are aware of the threats, and use subjectivity to fulfill the research objectives.
\end{abstract}

\section{Keywords: qualitative data, subjectivity}

\section{Some aspects of the qualitative data collection}

Observation is a method of data collection that consists in the recording of some features, behaviors or events related to the subject, as they are perceived by the researcher. Since the events are usually recorded on the camera, the inaccuracy of the data, which may be caused by the humans' faulty memory regarding the past or by the inadequate estimation of the present or future events, is to be eliminated. Some characteristics of the observational research are mentioned in the literature and refer to the following:

- events, actions, norms and visible values are seen through the researcher eyes;

- the reality is described using mundane details, that contribute to a proper understanding of what is happening in a particular context;

- researchers try to understand the events in a broader social and historical context;
- data earned are not statistics, but detailed field notes, observation reports, stories and reflections. [1]

Thus it is revealed the lack of a prior structure when using the observation for collecting data and also the difficulty to understand the meaning of data in that case.

Addressing the subject from another point of view, the psychologist Adriana Băban [2] considers that the interview is "the cornerstone of qualitative methodology", because to ask questions related to a sensitive topic and get some relevant and personal answers from a subject is a more difficult task than it seems to be at first sight. Despite this, at least two aspects can lead a researcher to choose the interview as the investigation technique: first, the concern for the subjective meanings that the participants would confer to a particular topic; secondly, the possibility to capture a lot of nuances and features considered being too complex for a quantitative investigation.

The version of structured and semi-structured group interview known as 
focus group is also used for exploratory purposes, because the interaction of the participants imply exchanging of ideas and opinions. When applying this method, beyond the general skills required to the researcher for conducting an interview, other skills related to the management of the group dynamics are also necessary: to encourage participants to express their views, to obtain answers from all the participants, to not let certain people to dominate the discussion and the group, to maintain the balance between his dual role as interviewer and moderator.

Other research methods do not imply the direct interaction between researcher and subjects, but the researcher progressive entry in the context of the subjects' life and work, through the gathering of relevant information. Thus, the case study research assumes that examining the context and other complex conditions related to a case being studied are integral to understanding the case. Robert Yin serves as its opinion about the case study as a research method [3]: "An empirical inquiry about a contemporary phenomenon (a "case"), set within its realworld context, especially when the boundaries between phenomenon and context are not clearly evident."

In the literature, all the methods mentioned above are considered to be questionable from the point of view of their scientific rigor: they can offer only a preview, an orientation, an introduction on the main topic, other methods (survey, experiment etc.) being more accurate for collecting data; they may not seem to protect sufficiently against such biases as a researcher seeming to find what she or he had set out to find; they also may suffer from a perceived inability to generalize the findings to any broader level.

\section{Outcomes of qualitative research}

Since the qualitative research involves most often addressing simple questions and receiving complicated answers, a laborious data processing should takes place after the collection of a big amount of information. The methods and techniques of analysis are meant to prepare the collected material for the subsequent operation, the data interpretation. So, to make a proper interpretation, the running of some preparatory operations is necessary: the reduction, condensation and selection of data by abstracting, encoding, and identification of the main topics; then the organization of data in various forms and structures, which assure a suggestive presentation and allow the easily extraction of the conclusion. The qualitative data that initially are complicated and untidy, can be arranged and organized as simple as possible by compiling and summarizing, without reducing them to numbers and operations with numbers. No matter what technique of data collecting is used, finally the researcher will get some notes, transcripts or recordings, some encoded and synthesized text and images, in the form of keywords, key points, codes etc. Then he will have to extract the signification of these.

In their final papers or reports, the researchers usually choose one of the following ways of interpretation and exploitation of the results of qualitative research: (1) the creation (developing, enunciation) of a theory, in an inductive manner, by identifying which are the main and also the common elements of all the particular situations that were studied, or (2) the creation (composing, writing) of a significant story from the field, which can (re)build a world by using the language and its registers. We will further detail both of these procedures.

Sometimes, a theory can be entirely generated from the data collected during the investigation. Another time, if formerly exist some substantiated theories, which are appropriated for the area of investigation, these may be progressively added or amended thru the comparison with the new data. In the qualitative research, a theory is not first 
generated and then tested. In fact, he is inductively and gradually derived from data collected during the investigation of some social phenomena; he is constantly discovered, developed and reviewed. In his studies, Mircea Agabrian explains that "the theory development means the organization of concepts and ideas in a systematic and explanatory flowchart. Any sentence or hypothesis derived from the prior collected data must be continuously checked by reference to the new data, and if necessary, must be retailed, extended or sometimes canceled." [4].

Concerned about the discovery and the understanding of a psychological or social phenomenon, researchers are interested in patterns of action and interaction between different social actors, without pursuing the creation of theories about individual actors. Once they have developed a hypothetical model or a provisional theory, the researchers focus on the eventual deviant cases, which do not fit to the hypothetical model or do not confirm it. Uwe Flick [5] finds that, at this point, the researcher usually has two choices: either reformulates the hypothetical model (theory), in order to match to the deviant case, or looks for the discovery of the cause of deviance. Generally, the discovery of the causes gives the researcher the possibility to exclude the deviant case (and other similar) from his study. Then he must restrict the applicability of the theory only to the remaining cases.

Another successful way of condensation and presentation of the results of qualitative research is the meaningful story. This procedure is chosen "when the collected data are unusual, surprising, and unique, or include extraordinary, spectacular people, events or phenomena, which are not common or accessible" [6]. The researcher subjectively addresses this technique, trying to center all the data on certain ideas, considered to be important. He can interpret the data in the light of his personal experience, or can opt for a more objective approach, using a descriptive style, trying to "stand aside" and to let the described world to speak for itself.

\section{Features of qualitative data processing}

The objectivity is a very controversial topic in the debate on the scientific nature of the qualitative research. Approaching this issue from the standpoint of a specialist in communication and public relations, Corina Sîrb believes that it is not possible to speak about an objective qualitative research, in the absolute sense of the word, because the one who conducts the data collection is the same with the one who makes the data interpretation. Whereas in the quantitative research there are used specific tools, such as questionnaires, in the case of qualitative research, the main tool is the researcher himself. Therefore, qualitative research is "so condemned to subjectivity" [7].

In fact, all researchers in the social sciences, no matter if they are qualitative or quantitative oriented, are concerned about the extent to which the data are objective. We will present some considerations regarding the objectivity of knowledge, both from the standpoint of quantitative research (with references from the positivist paradigm) and the qualitative research positions (with reference from the constructivist paradigm).

Table 1: Characteristics of the positivist knowledge and the constructivist knowledge of the social reality (adapted from Elisabeta Stănciulescu [8])

\section{Positivist knowledge}

Objectivity - Represents the correspondence between the knowledge produced by people and the reality to which they refer; focus on the

\section{Constructivist knowledge}

Objectification - Objectivity is no more than an ideal, which can not be fully reached; focus on the process of knowledge, on how to get to the 


\begin{tabular}{|ll|}
\hline \multicolumn{1}{l}{ Positivist knowledge } \\
$\begin{array}{l}\text { product of knowledge, considered to be } \\
\text { objective truths. }\end{array}$
\end{tabular}

Since the interpretation of the results of psychological and social investigations often takes the form of explanations, researchers might not be always fully aware of the differences between two actions: interpretation and explanation of the results. The expression commonly used by researchers is like this: when $A$ happens, then, due to the circumstances, $B$ will appear, according to some natural or social regularity, according to rules, principles of operation, etc. But there are some important differences between the interpretation and the explanation of the results of a social research. Erick Maaloe believes that "to interpret an aspect which he noted, the investigator should look into the past, take into consideration other existing data and try to understand what happened, whilst to explain the same issue, the researcher will look forward, and will try to describe regularities or logical connections between events and circumstances that occurred"'[9]. As a consequence, he will be able to make predictions about what follows, make recommendations or identify possible ways forward so as the research beneficiaries to fulfill their goals. In brief, to explain a phenomenon, it is not enough simply identify and mention the chain of facts or past events, it is imperative to refer to the reasons, causes or opportunities.

The same scholar classify explanations of the results in two categories, as the following [10]: weak explanations, those offering the public a rule that helps to predict how someone (an individual or a group of persons) will act or will react in certain circumstances; and solid explanations, those helping public to understand the functioning rule.

The analysis of data is an essential 
step of a qualitative research, when the researcher' creativity comes into action and needs to be combined with his keen mind, his professional expertise and his experience. In a recently published study, Matthew Miles and his collaborators [11] present several strategies that could be use for data analysis: case-oriented, variableoriented and interactive synthesis strategy.

The case-oriented strategy (focus on topic or group) involves the analysis of the first case and the development of an analytical model (the first frame or pattern of analysis). Then the researcher passes to the second cases, aiming the discovery and the shaping of the second case model. He subsequently makes a comparative examination of the models and monitors whether the patterns match and the new cases share the same configuration. He will finally establish and will design one representative model, which is to be suitable for all analyzed cases. This is achieved by modifying and improving successive models through the systematic comparisons. The variables-oriented strategy involves identifying and cropping the themes that occur in the analyzed cases and then making their analysis as a whole. This strategy is usually used for analyzing the results of focus group meetings. In addition, the above mentioned authors indicate the interactive synthesis strategy, as a phenomenological approach of data analysis, which first requires the summaries of every individual case. Then a storytelling will be done based on these summaries, and finally the researcher must condense them into a single story. This final story will be compared to the initial summaries of the cases, so the researcher to be sure that it fits to each case.

In an article that argues the possible positive effects of subjectivity in social studies, Martin Drapeau states that the subjective analysis can be included in a research project as it can serve two fundamental purposes: it helps to understand the object of investigation and it helps to understand how the significant personal relationships may influence data analysis and understanding. „But for those who wish to make use of subjectivity in a research setting, many precautions such as the ones suggested in the literature must be taken: triangulation, consensus, text-based analysis, introspective work of the researcher, and so on" [12].

\section{Final considerations}

Generally speaking, subjectivism might become a self-conscious and selfassured claim with a wide range of nuances. Fortunately, people do perceive the word in their personal way, but some disagreements could rise when the researchers are not aware and don't accept their potential for being biased. In these circumstances, the researcher himself, not only his subjects, could become an interesting object of psychological and social investigation. In fact, he has to make a lot of sensitive and subjective decisions related to which data are significant and reliable and which are not, what the personal significance of the data is and what data could have a broader signification. The subjectivity becomes a source of inspiration for further research and a way to deepen the understanding of human behavior and beliefs.

\section{References}

[1] G. Guest, E.E. Namey, M.L. Mitchell, Collecting Qualitative Data: A Field Manual for Applied Research, London, Sage Publications, 2013.

[2] A. Băban, "Strategii şi metode de cercetare calitativă", Cogniţie, Creier, Comportament, No. 4, 2000, p.319.

[3] R.K. Yin, Case Study Research: Design and Methods, 4-th Edition, Sage Publications, Thousand Oaks, 2009, p.18.

[4] M. Agabrian, Cercetarea calitativă a socialului, Institutul European, Iaşi, 2004, p.174. 
[5] U. Flick, An Introduction to Qualitative Research, 4-th Edition, Sage Publications, Londra, 2009.

[6] F. Scârneci, Indrumar de cercetare calitativă în ştiinţele socio-umane, Editura Universităţii Transilvania, Braşov, 2006, p. 121.

[7] http://ctrl-d.ro/inspiratie/tehnici-de-cercetare-calitativa/

[8] E. Stănciulescu, Specificul cercetării calitative, online: http://elisabetastanciulescu.ro/wpcontent/uploads/2011/03/Specificul-cercetarii-calitative Constructivism obiectivare validitate fiabilitate Etica-cercetarii-stiintifice.pdf

[9] E. Maaloe, Explanation and interpretation in Social Sciences, 2015, p. 26, online: http://bookboon.com/en/explanation-and-interpretation-in-social-science-ebook

[10]Ibidem, p.34.

[11]M. Miles, M. Huberman, J. Saldana, Qualitative Data Analysis, 3-th Edition, Sage Publication, 2014.

[12]M. Drapeau, Subjectivity in research: Why not? But..., The Qualitative Report, Vol.7, No. 3, 2002, http://www.nova.edu/ssss/QR/QR7-3/drapeau.html 